\title{
DEVELOPMENT AND CHARACTERIZATION OF MUCOADHESIVE-THERMOSENSITIVE BUCCAL GEL CONTAINING METRONIDAZOLE FOR THE TREATMENT OF ORAL MUCOSITIS
}

\author{
ORAL MUKOZIT TEDAVISİ IÇIN METRONIDAZOL IÇEREN MUKOADEZIF-ISIYA \\ DUYARLI BUKKAL JELIN GELISSTIRILMESİ VE KARAKTERİZASYONU
}

\section{Melike ONGUN, Emre TUNÇEL, Esra KODAN, Fatmanur TUĞCU-DEMIRÖZ*, Fahriye Figen TIRNAKSIZ}

Gazi University, Faculty of Pharmacy, Department of Pharmaceutical Technology, 06330, Etiler, Ankara, TURKEY

\begin{abstract}
Objective: This study was aimed to develop and characterize, mucoadhesive-thermosensitive gel formulation containing metronidazole that can quickly gel at the buccal mucosa temperature for treatment of oral mucositis.

Material and Method: In this study, the combinations Poloxamer 407 (P407), Poloxamer 188 (P188) and Hydroxypropyl methylcellulose (HPMC) were used in certain concentrations to form a gel in buccal mисоsa. Optimum formulations were selected by measuring the gelling time and gelling temperature of the formulations prepared. The hardness, adhesiveness, cohesiveness, resilience, sprayability, mucoadhesion and release properties of selected formulations were evaluated.

Result and Discussion: The results showed that F1 and F3 formulations, which quickly turn into gel form at $33{ }^{\circ} \mathrm{C}$, could be the optimum formulations. These two formulations showed controlled release for 8 hours. Texture profile analysis (TPA), mucoadhesion studies and sprayability studies have shown that F1 formulation which the mixture of P407 (15\%), P188 (20\%) and HPMC (5\%) is the optimum formulation for the buccal mисоsa. In conclusion, mисоаdhesive-thermosensitive gels containing metronidazole may be a good alternative in the treatment of oral mucositis.

Keywords: Metronidazole, mucoadhesive-thermosensitive gel, oral mucositis, poloxamer
\end{abstract}

\footnotetext{
* Corresponding Author/Sorumlu Yazar: Fatmanur Tuğcu-Demiröz

e-mail/e-posta: fatmanur@gazi.edu.tr
} 


\section{ÖZ}

Amaç: Bu çalışmada oral mukozit tedavisi için bukkal mukoza sıcaklı̆̆ında hızla jelleşebilen, metronidazol içeren mukoadhesif-ısıya duyarlı jel formülasyonu hazırlanması ve karakterize edilmesi amaçlanmıştır.

Gereç ve Yöntem: Bu çalışmada, belirli konsantrasyonlarda poloksamer 407 (P407), poloksamer 188 (P188) ve hidroksipropil metilselüloz (HPMC) kombinasyonlarl, bukkal mukozada jel oluşturmak için kullanılmıştır. Optimum formülasyonlar hazırlanan formülasyonların jelleşme süresi ve jelleşme sıcaklığl ölçülerek seçilmiştir. Seçilen formülasyonların sertlik, adhezif, kohezif, esneklik, püskürtülebilirlik, mukoadhezif ve salım özellikleri değerlendirilmiştir.

Sonuç ve Tartışma: Sonuçlar, $33^{\circ} C^{\prime}$ de hızla jel formuna dönüşen F1 ve F3 formülasyonunun optimum formülasyonlar olabileceğini göstermiştir. Bu iki formülasyon 8 saat boyunca kontrollü salım göstermiştir. Doku profili analizi (TPA), mukoadhezyon ve püskürtülebilirlik çalışmaları, F1 formülasyonun, P407 (\% 15), P188 (\% 20) ve HPMC (\% 5) kombinasyonu, bukkal mukoza için optimum formülasyon olduğunu göstermiştir. Sonuç olarak, metronidazol içeren mukoadhezif-ısıya duyarl jeller oral mukozit tedavisinde iyi bir alternatif olabilir.

Anahtar Kelimeler: Metronidazol, mukoadhezif-lslya duyarlı jel, oral mukozit, poloksamer

\section{INTRODUCTION}

Mucositis, an inflammation of the oral mucosa, appeared in the 1980s. Oral mucositis occurs in almost all head and neck cancer patients receiving high doses of chemotherapy or radiotherapy, in about $70 \%$ of patients receiving treatment for stem cell transplantation and in about $30 \%$ of patients receiving conventional chemotherapy. Oral mucosal epithelial cells, which have the ability to divide faster than other cells, are the most affected cells during chemotherapy [1-4]. In addition, as oral mucositis makes the patient vulnerable to infections, it causes the development of opportunistic infections and increases the cost of treatment by extending the mortality and length of hospital stay. Mucositis in cancer patients can decrease the patient's quality of life. It causes inadequate oral intake and loss of body weight [5]. Since there is no effective treatment for mucositis or the pain it causes, many studies have been conducted in this area. Various strategies have been developed for treatment, such as low-level laser therapy, anti-inflammatory agents, oral decontamination, analgesics, or washing with opioids [6]. In the treatment of pain caused by oral mucositis, mixtures of oral solutions, commonly known as 'Magic Mouth Water', containing different amounts of diphenhydramine, viscous lidocaine, bismuth subsalicylate, and corticosteroids can be used [7]. There are products in the pharmaceutical market in the form of oral gels and liquids, such as Peridex ${ }^{\circledR}$ and Gelclair ${ }^{\circledR}[8,9]$.

Numerous bacteria that form normal oral flora can become pathogenic by immunosuppression. Examples of these bacteria are Actinobacillus, Fusobacterium, Actinomycetemcomitans species, which are usually found in the gram-negative anaerobic group and cause oral mucosal infection. 
Metronidazole has a lethal effect on these gram-negative anaerobic bacteria, which can become pathological as a result of immunosuppression. The use of metronidazole in the treatment of oral wounds can be preferred due to its limited side effects and inexpensiveness. Many studies have been conducted on the use of metronidazole topically in the treatment of various oral infections, such as periodontitis and gingivitis [10].

Topical treatment is frequently used for the prevention or treatment of diseases locally $[11,12]$. Gels are commonly preferred because they are easy to prepare and can be used as carrier systems for both lipophilic and hydrophilic agents. Gels are systems that consist of two components which are cross-linked in 3D. The gel structure can consist of inorganic molecules, primarily polymers or organic macromolecules [13]. Hydrogels are often preferred because they have advantages such as high patient compliance, while the aqueous structure provides ease of application and preparation [14]. Poloxamers, which are nonionic poly (ethylene oxide) (PEO)-poly (propylene oxide) (PPO) triblock copolymers, are used very frequently in pharmaceutical formulations as surfactants, emulsifying agents, solubilizing agents, dispersing agents, and in vivo absorbance enhancers [15]. Poloxamers, which are approved by FDA, also called "functional excipients" because they are essential ingredients and play an important role in the formulation [16]. Due to their inverse thermosensitive properties, especially poloxamer 188 (P188) and poloxamer 407 (P407) are frequently used in pharmaceutical formulations [17]. While P407 contains 70\% hydrophilic PEO and $30 \%$ hydrophobic PPO, P188 contains approximately 80\% POE units and 20\% PPO units [18-20]. Mucoadhesive polymers can be added to pharmaceutical formulations prepared with poloxamers and are planned to be administered mucosally. Mucoadhesive polymers are widely used in pharmaceutical formulations to increase the residence time of the prepared formulation on the mucosa. Examples of these polymers are polyacrylic acid derivatives such as carbomer and polycarbophil, cellulose derivatives, chitosan and its derivatives, hyaluronic acid, alginate, carrageenan and guar gum [21,22].

In this study, mucoadhesive-thermosensitive gels containing metronidazole were developed to the buccal mucosa for the treatment of oral mucositis. This study also, instead of using high doses of metronidazole for systemic effect was based on the idea that it would be more effective to reduce side effects and increase patient compliance by developing a topical formulation at low doses. It was thought that when metronidazole was used in low doses, a homogeneous unit dose content could be provided as it dissolved in the prepared gel. Based on these considerations, the lowest $(0.5 \%)$ metronidazole dose used in commercial products is intended to be used in gel formulations developed. Poloxamers are polymers that do not have a mucoadhesive feature, and therefore retention times in mucosal tissues are short. Thus, mucoadhesive substances can be added to the gel structure 
to improve their mucoadhesive properties. In our study, hydroxypropyl methylcellulose (HPMC), a cellulose derivative, was used as a mucoadhesive polymer. The goal was to develop a formulation that can be sprayed at room temperature, is able to provide controlled metronidazole release and applied once a day. Thus, patient compliance will be increased, and one of the side effects that the patient is exposed to in cancer treatment can be reduced. Primarily, gelling temperature and gelling time tests were performed on the prepared gel formulations. Afterwards, rheological studies, texture profile analysis, mucoadhesion studies, in vitro drug release study, and sprayability studies were performed in the selected formulations.

\section{MATERIAL AND METHOD}

\section{Materials}

Metronidazole was obtained from Abdi Ibrahim Pharmaceutical Company (Turkey). Poloxamer 188 (Lutrol ${ }^{\circledR}$ F68), poloxamer 407 (Lutrol ${ }^{\circledR}$ F127) and hydroxypropyl methylcellulose (HPMC, Methocel K100MCR Premium USP/EP) were provided from BASF (Germany) and Colorcon (UK), respectively. All other chemicals and reagents were of analytical grade.

Simulated Saliva (SS) at pH 6.8 was prepared. One liter of SS had the following composition: $\mathrm{Na}_{2} \mathrm{HPO}_{4}(2.38 \mathrm{~g}) \mathrm{KH}_{2} \mathrm{PO}_{4}(10.19 \mathrm{~g}), \mathrm{NaCl}(8.00 \mathrm{~g}), \mathrm{H}_{3} \mathrm{PO}_{4}$ to adjust the final $\mathrm{pH}$ to 6.8 (pH meter, Schott CG 840, Germany), distilled water (1000 ml) [23].

\section{Preparation of mucoadhesive-thermosensitive gel formulations}

The mucoadhesive-thermosensitive gels were prepared according to cold method [24]. First, metronidazole was dissolved in distilled water at a concentration of $0.5 \%(\mathrm{w} / \mathrm{w})$. Then, $0.5 \%(\mathrm{w} / \mathrm{w})$ of HPMC was slowly added into metronidazole solution under magnetic stirring (600 rpm) at room temperature. This mixture was stirred at the room temperature for $1 \mathrm{~h}$ to obtain a homogeneous solution. Then P407 and P188 were slowly added to the HPMC solution containing metronidazole in an ice bath and under magnetic stirring $(1000 \mathrm{rpm})$. The mixture was maintained under mild magnetic stirring (400 rpm) in ice bath overnight to allow complete dissolution.

\section{Characterization of mucoadhesive-thermosensitive gel formulations}

\section{Appearance}

Mucoadhesive-thermosensitive formulations were visually evaluated in terms of clarity, color and particle content in sol and gel states. 


\section{Determination of sol/gel temperature and time $\left(T_{\text {sol-gel }}\right)$}

The formulation prepared as $20 \mathrm{~g}$ in a beaker at room temperature was mixed at $50 \mathrm{rpm}$ by throwing a magnet on a heated magnetic stirrer. The temperature was gradually increased and controlled with the probe of the mixer. The temperature, at which the magnet in the formulation stopped due to gelation, was reported as gelation temperature $\left(\mathrm{T}_{\text {gel }}\left({ }^{\circ} \mathrm{C}\right)\right)$ [25]. The transition time (Tgel (sec)) from sol to gel was determined by holding the stopwatch. Experiments were carried out at least three times.

\section{Drug content uniformity}

$0.2 \mathrm{~g}$ gel formulation containing metronidazole was weighed with high precision. The weighted gel formulation was mixed in a $100 \mathrm{~mL}$ of $\mathrm{pH} 6.8$ phosphate buffer for 24 hours at room temperature and $100 \mathrm{rpm}$ on a magnetic stirrer. Metronidazole concentration was measured at 320 $\mathrm{nm}$ via UV spectrophotometer [26].

\section{Rheological studies of the mucoadhesive-thermosensitive gel formulations}

The rheological analysis of the formulations was performed both at $25{ }^{\circ} \mathrm{C}$ and $33{ }^{\circ} \mathrm{C}$ using Brookfield DV - III + Rheometer. The formulations were kept at room temperature $\left(25^{\circ} \mathrm{C}\right)$ and 33 ${ }^{\circ} \mathrm{C}$ in a water bath, and shear stress values were measured as a function of different shear rate values. Viscosities were calculated using shear rate $(\dot{\mathrm{y}})$ and shear stress $(\sigma s)$. For pseudoplastic (shearthinning) and dilatant (shear thickening) systems, the relationship between shear stress and shear rate is expressed by a power law model (also known as The Ostwald de Waele model). $\mathrm{K}$ is the consistency coefficient and $\mathrm{n}$ is the non-Newtonian index (Eq. 1). As $\mathrm{K}$ increases, the viscosity of the system increases. The power law index $n$ characterizes the rheological behavior of the samples. For the pseudoplastic systems $n<1$, for the dilatant systems $n>1$, and for the Newtonian systems $\mathrm{n}=1[27]$.

$$
\sigma \mathrm{s}=\mathrm{K}(\dot{\mathrm{y}})^{\mathrm{n}}(\text { Eq. 1) }
$$

The curve of the logarithms of the shear stress versus the logarithms of the shear rates is expressed a slope of $\mathrm{n}$ and an intercept of K (Eq. 2).

$$
\log (\sigma \mathrm{s})=\log \mathrm{K}+\mathrm{n} \log (\dot{\mathrm{y}})(\text { Eq. } 2)
$$

\section{Determining mechanical parameters of the mucoadhesive-thermosensitive gel formulations}

Mechanical parameters such as hardness, adhesiveness, cohesiveness and resilience of chosen gel formulations were determined using a TA-XT Plus Texture Analyzer (Stable Micro Systems, 
London, UK) equipped with a $5 \mathrm{~kg}$ load cell in TPA mode [28]. The gels were placed in a water bath to maintain at $33{ }^{\circ} \mathrm{C}$. The $50 \mathrm{~mm}$ diameter back extrusion rig is immersed in chosen gel formulations at a speed of $2 \mathrm{~mm} / \mathrm{s}$ by $15 \mathrm{~mm}$. The hardness $(\mathrm{N})$, adhesiveness $(\mathrm{N} \mathrm{mm})$, cohesiveness and elasticity of the gel formulations were determined using the force-time plot $[24,29]$. The adhesiveness is a necessary property to detaching the probe from the sample. Adhesiveness is a property related to mucoadhesion [28]. Hardness expresses the force required to attain a given deformation. Cohesiveness is the ratio of the area under the force-time curve produced on the second compression cycle to that produced on the first compression cycle [30]. The resilience defines the rate at which the deformed formulation returns to its undeformed condition.

\section{Ex-vivo mucoadhesion studies of the gel formulations}

The ex-vivo mucoadhesion test of the optimum poloxamer-HPMC gels were performed using a TA-XT Plus Texture Analyzer with a holder. Bovine cheek mucosa frozen at $-20{ }^{\circ} \mathrm{C}$ was brought to $33{ }^{\circ} \mathrm{C}$ and a $2 \mathrm{~mm}$ thick section was taken through the surface of this mucosa and attached to the lower end of the device probe. About $1 \mathrm{~g}$ of gel and mucosa were contacted for 30 seconds. The instrumental parameters were specified in a previous study [25]. Mucoadhesion data were obtained by calculating the area under the curve from the force-distance plot as the work of mucoadhesion [24]. The Eq. 3 was used to calculate the work of mucoadhesion per $\mathrm{cm}^{2}\left(\mathrm{~mJ} \cdot \mathrm{cm}^{-2}\right) .\left(\pi \mathrm{r}^{2}\right.$ : the area of the mucosal surface being in contact with hydrogel)

$$
\text { Work of mucoadhesion }\left(\mathrm{mJ} / \mathrm{cm}^{2}\right): \frac{A U C}{\pi r^{2}}(\text { Eq.3) }
$$

\section{In vitro drug release study}

The in vitro drug release study was carried out with dialysis membrane in SS medium pH 6.8 at $33{ }^{\circ} \mathrm{C}$ by using Franz diffusion cell. At predetermined time intervals $(0.25,0.5,1,2,3,4,6$ and 8 h), $2.5 \mathrm{~mL}$ release medium was taken out for analysis and completed with fresh buffer $(\mathrm{n}=3)$. Samples were measured spectrophotometrically at $320 \mathrm{~nm}$.

\section{Drug release kinetic profiles}

To study the drug release kinetics and mechanism of gel formulations containing metronidazole, the in vitro data was evaluated to find a suitable mathematical model to fit zero order, first order, Higuchi, Korsmeyer-Peppas, Hixson-Crowell, Weibull release kinetic models by DDsolver software. Adjusted coefficient of determination $\left(\mathrm{r}^{2}{ }_{\text {adj }}\right.$ ), Akaike information criterion (AIC) and model selection criteria (MSC) were used as fitting parameters [31]. 


\section{Spraying ability assay}

$\mathrm{F} 1$ and $\mathrm{F} 3$ formulations were cooled in the refrigerator, filled in $50 \mathrm{~mL}$ polyethylene bottles in fluid form, and closed with a spray pump. Spraying of the formulations from the spray pump was recorded with a video camera [32].

\section{RESULT AND DISCUSSION}

\section{Preparation of mucoadhesive-thermosensitive gel formulations}

Poloxamers are amphiphilic triblock copolymers that show in situ gelling at different temperatures when mixed in different proportions in the presence of different additives. It is possible that the prepared formulation can be locally effective by in situ gelling in the buccal region. In situ gelling, as well as easy of application, can provide that the formulation remains on the local lesions of the oral mucositis for a long time and can achieve antimicrobial agents such as metronidazole more successfully in the treatment of local lesions. Different poloxamer types and proportions were tried for preparing mucoadhesive-thermosensitive gel (Table 1).

While all formulations were transparent and in the fluid form at refrigerator temperature, some of the formulations started to gel at room temperature and transformed into a slightly cloudy gel form. No particle content was observed in any of the sol and gel forms. After metronidazole addition, colors of the mixtures turned to slightly yellow.

Table 1. Composition of different gel formulations

\begin{tabular}{|c|c|c|c|}
\hline Formulation code & P407 concentration (\% w/w) & P188 concentration (\% w/w) & HPMC concentration (\% w/w) \\
\hline F1 & 15 & 20 & 0.5 \\
\hline F2 & 15 & 20 & - \\
\hline F3 & 20 & 15 & 0.5 \\
\hline F4 & 20 & 15 & - \\
\hline F5 & 15 & - & - \\
\hline F6 & 15 & - & 0.5 \\
\hline F7 & 20 & - & - \\
\hline F8 & 20 & - & - \\
\hline F9 & - & 20 & - \\
\hline F10 & - & 15 & 0.5 \\
\hline F11 & - & 20 & 0.5 \\
\hline F12 & - & 15 & \\
\hline
\end{tabular}




\section{Characterization of gel formulations}

\section{Determination of poloxamer ratios and measurements of sol/gel transition temperature and time}

Oral mucosa temperature is $35.8-37.3{ }^{\circ} \mathrm{C}$ [33]. However, the temperature changes during the 24-hour period depending on various factors (such as mouth breathing, food intake, etc.) [34]. In order to take these temperature changes into account, the temperature inside the mouth was accepted as $33^{\circ} \mathrm{C}$. Gel formulations are intended to have a gelling temperature of $28-33^{\circ} \mathrm{C}$ for complete gelling in the mouth. The optimum formulation was determined by taking into account the gelling temperature. In a previous study, the gelling temperature in this range was achieved with a ratio of about 20\% (w/w) P407 [22]. In addition to 20\% (w/w) P407, addition of P188 was found to be important for keeping the gelling temperature in the range of $30-33{ }^{\circ} \mathrm{C}$. According to results of previous studies, it was found that the increase of P188 ratio did not cause a regular increase in gelling temperature. It was aimed to increase the viscosity by increasing the total polymer concentration in order to prolong the gel formulation residence time in the oral mucosa. For this reason, $\mathrm{P} 188$ ratio was chosen as $15 \%[35,36]$. The gelling time and temperatures of the formulations were compared with 20\%, 15\% and 0\% (w/w) P407 and P188, and in the presence and absence of $0.5 \%(\mathrm{w} / \mathrm{w})$ HPMC (Table 2).

Table 2. Gelation time (Tgel $(\mathrm{sec}))$ and temperature $\left(\mathrm{T}_{\text {gel }}\left({ }^{\circ} \mathrm{C}\right)\right)$ of formulations with or without HPMC containing different proportions P407 and P188 (n=3).

\begin{tabular}{|c|c|c|c|c|c|}
\hline Formulations & P407 \% (w/w) & P188 \% (w/w) & $\begin{array}{c}\text { HPMC \% } \\
(\mathbf{w} / \mathbf{w})\end{array}$ & $\mathbf{T}_{\text {gel }}\left(\mathbf{C}^{\circ}\right)$ & $\left.\begin{array}{c}\mathbf{T}_{\text {gel }} \text { (sec) (Room } \\
\text { Temperature to 33 }\end{array}{ }^{\circ} \mathbf{C}\right)$ \\
\hline F1 & 15 & 20 & 0.5 & $31.87 \pm 2.48$ & $107.67 \pm 3.68$ \\
\hline F2 & 15 & 20 & - & $36.5 \pm 1.15$ & $600<$ \\
\hline F3 & 20 & 15 & 0.5 & $28.13 \pm 0.95$ & $68.00 \pm 6.38$ \\
\hline F4 & 20 & 15 & - & $24.00 \pm 4.68$ & $138.00 \pm 20.85$ \\
\hline F5 & 15 & - & 0.5 & $20.60 \pm 0.53$ & $13.66 \pm 4.64$ \\
\hline F6 & 15 & - & - & $22.90 \pm 3.06$ & $26.33 \pm 14.38$ \\
\hline F7 & 20 & - & 0.5 & $19.80 \pm 1.80$ & $3.33 \pm 4.71$ \\
\hline F8 & 20 & - & - & $20.80 \pm 0.87$ & $13.66 \pm 4.64$ \\
\hline F9 & - & 15 & - & $85<$ & $600<$ \\
\hline F10 & - & 20 & 0.5 & $85<$ & $600<$ \\
\hline F11 & - & 15 & 0.5 & $85<$ & $600<$ \\
\hline F12 & - & & - & $600<$ \\
\hline
\end{tabular}


According to the results obtained, it was observed that the gelling time and temperature of F1 formulation containing 15\% (w/w) P407, 20\% (w/w) P188 and 0.5\% (w/w) HPMC were in the desired range. In formulations containing only P407 without P188 the presence of HPMC were seen to reduce the gelling temperature. The effect of HPMC addition on the gelling temperature was different in the F1 and F3 formulations. The gelling temperature in F1 decreased with the addition of HPMC but increased in F3. In another study which P407 was used alone it was noted that the addition of HPMC reduced the gelling temperature [36]. Ban et al. have shown that addition of PEG400 to formulations containing P407 and P188 reduces the gelling temperature [35]. Koffi et al. found that propanediol-1,2 decreased the gelling temperature of the formulations prepared with P407 alone, while the addition of HPMC increased the gelling temperature of P407 and propanediol-1,2 formulations. However, the increase in the amount of HPMC caused a reduction in the gelling temperature [38]. These results support the conclusion that the presence of HPMC (as a different additive like PEG or propanediol-1,2) reduces gelling temperature in the formulations that we used P407 alone. In formulations containing only P188, $\mathrm{T}_{\text {gel }}$ could not be detected because the magnet did not stop at any temperature. It has been determined that the increase in P188 concentration cause an increase in the gelling temperature and gelling time (Figure 1 and Figure 2). Studies have shown that the increase of P188 concentration at constant P407 concentration does not cause a regular increase in gelling temperature [36,39]. The addition of HPMC reduced gelling time in all formulations. (Figure 2).

During this study, room temperature was not controlled as the formulations would have been under real conditions of use. Depending on the instantaneous room temperature, formulations with low gelling temperature were able to maintain their sol state. As a result, the gelling times of all formulations were measured. When the formulations were ranked according to the decreasing P407 ratio as the primary ranking criterion and the increasing P188 ratio as the secondary ranking criterion, the gelling times of the formulations showed a regular increase (Figure 2). However, the gelling temperature did not increase regularly. (Figure 1). Subsequent studies were carried out on F1 and F3 formulations due to the desired gelling temperature and acceptable gelling time. After the addition of metronidazole, a decrease was observed in the gelling temperatures and times of F1 and F3 formulations. The gelling temperature of the F1 formulation remained within the desired range (Table 3). Formulations F1 and F3 were chosen to evaluate rheological, mucoadhesive, textural and release properties. 


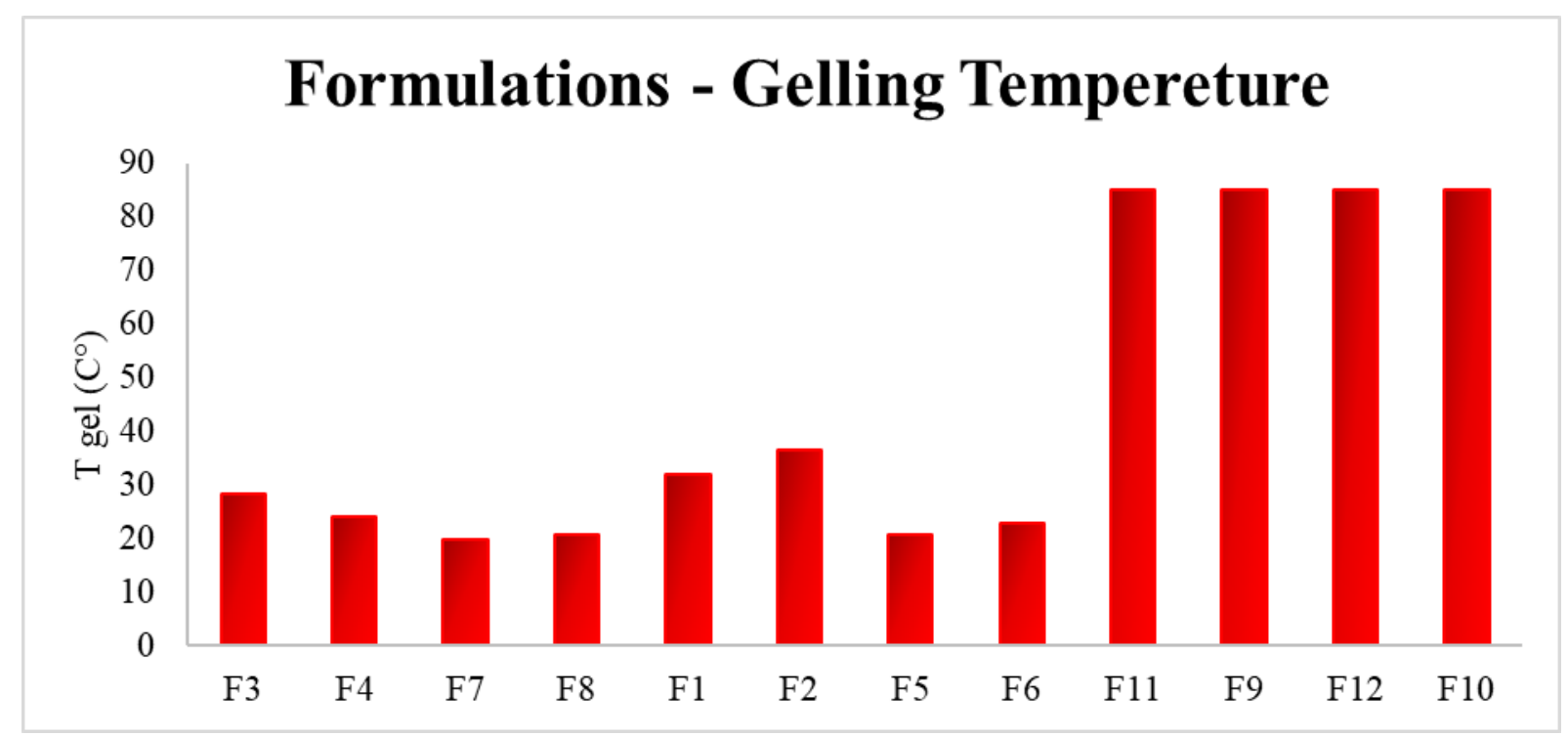

Figure 1. The formulations were sorted against gelling temperature according to the decreasing P407 ratio as the primary ranking criterion and increasing P188 ratio as the secondary ranking criterion.

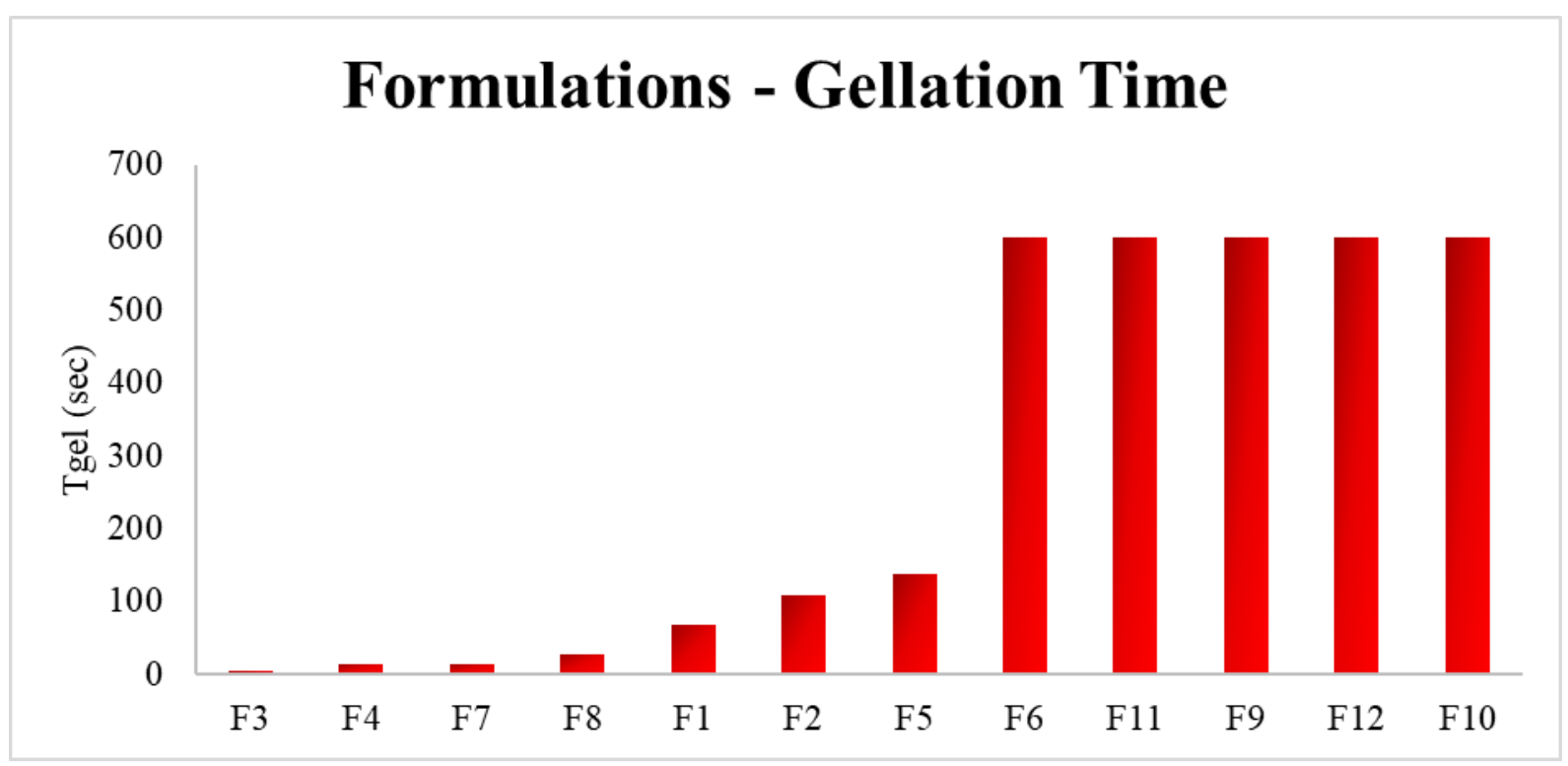

Figure 2. The formulations were sorted against gelation time according to the decreasing P407 ratio as the primary ranking criterion and increasing P188 ratio as the secondary ranking criterion. 
Table 3. Gelation time and temperature of $\mathrm{F} 1$ and $\mathrm{F} 3$ formulations after metronidazole addition $(\mathrm{n}=3)$

\begin{tabular}{|c|c|c|c|c|c|c|}
\hline $\begin{array}{c}\text { Form } \\
\text { ulatio } \\
\text { ns }\end{array}$ & $\begin{array}{c}\mathbf{P 4 0 7} \% \\
(\mathbf{w} / \mathbf{w})\end{array}$ & $\begin{array}{c}\mathbf{P 1 8 8} \% \\
(\mathbf{w} / \mathbf{w})\end{array}$ & $\begin{array}{c}\text { HPMC \% } \\
(\mathbf{w} / \mathbf{w})\end{array}$ & $\begin{array}{c}\text { Metronidazole \% } \\
(\mathbf{w} / \mathbf{w})\end{array}$ & $\mathbf{T}_{\text {gel }}\left(\mathbf{C}^{\circ}\right)$ & $\begin{array}{c}\mathbf{T}_{\text {gel }}(\mathbf{s e c})(\mathbf{R o o m} \\
\text { Temperature to } \\
\left.\mathbf{3 3}^{\circ} \mathbf{C}\right)\end{array}$ \\
\hline F1 & 15 & 20 & 0.5 & 0.5 & $30.4 \pm 0.58$ & $92.3 \pm 19.0$ \\
\hline F3 & 20 & 15 & 0.5 & 0.5 & $26.4 \pm 0.42$ & $16.0 \pm 5.57$ \\
\hline
\end{tabular}

After addition of metronidazole, there was no significant difference between Tgel $\left(\mathrm{C}^{\circ}\right)$ values $(\mathrm{p}<0.05)$.

\section{Drug content uniformity}

The used spectrophotometric method for metronidazole analysis was found to be linear $\left(r^{2}=0.9954\right)$. Finally, the amount of metronidazole in the F1 and F3 formulations was found as $106 \pm 2.09 \%$ and $104 \pm 1.10 \%$, respectively.

\section{Rheological Studies}

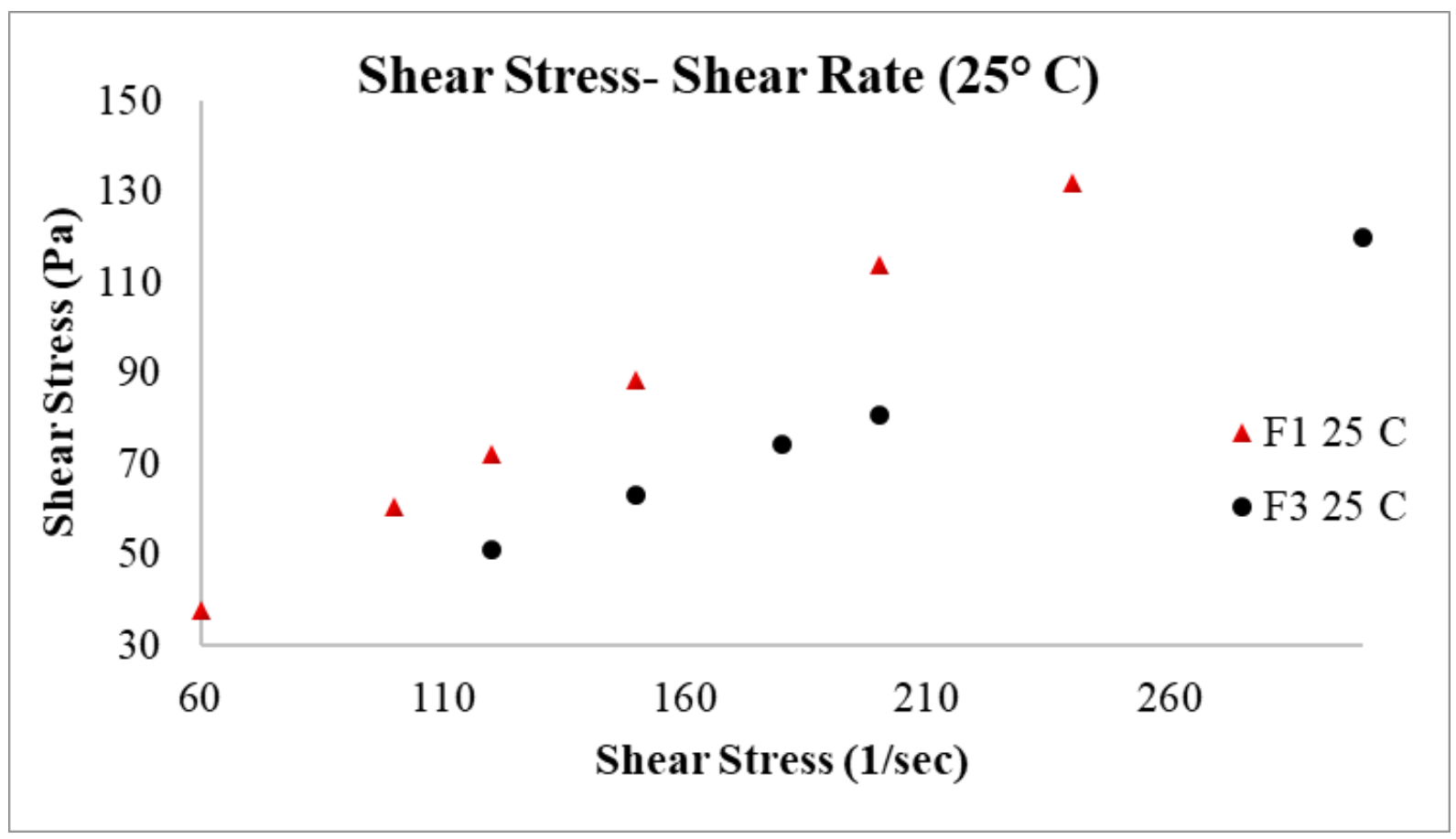

Figure 3. Viscosity (mPa.s)-Shear rate $(1 / \mathrm{sec})$ rheogram of $\mathrm{F} 1$ and $\mathrm{F} 3$ formulations at $25^{\circ} \mathrm{C}(\mathrm{n}=3)$. 


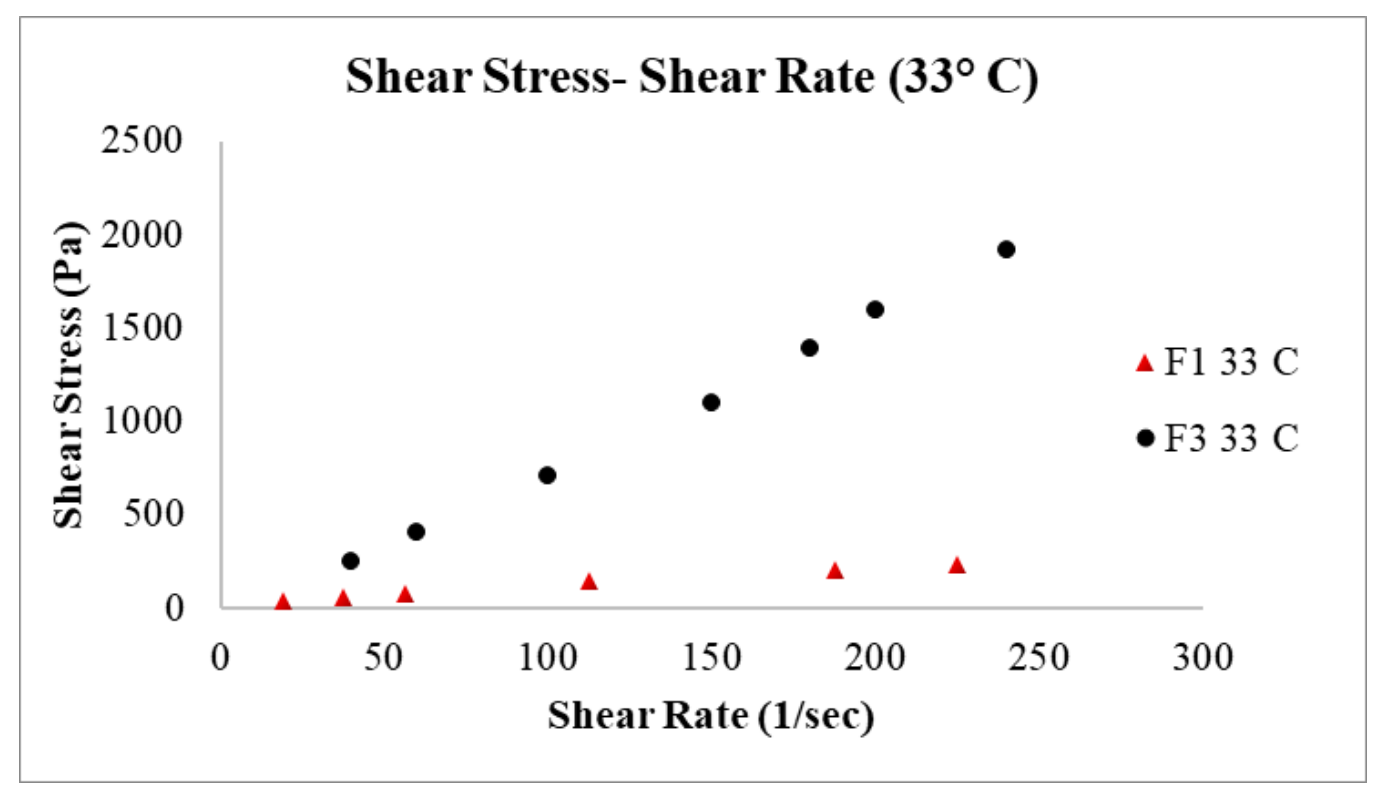

Figure 4. Viscosity (mPa.s)-Shear rate $(1 / \mathrm{sec})$ rheogram of $\mathrm{F} 1$ and $\mathrm{F} 3$ formulations at $33^{\circ} \mathrm{C}(\mathrm{n}=3)$.

Semi-solid systems have the advantage of ensuring that the formulation comes out of the package in the desired amount and remains in the infection area for the desired time. However, oily systems such as ointments and creams are not well tolerated by patients when applied to the mouth area due to their high viscosity values. For this reason, it will be advantageous to prepare the oral formulation as a water-based gel. Rheological properties are important factors that determine the gelling properties of thermosensitive hydrogels. The formulation should have low viscosity at room temperature and high viscosity to prevent flow and removal at $33^{\circ} \mathrm{C}[40]$.

All prepared formulations were in liquid form at refrigerator temperature. F1 and F3 formulations exhibited non-newtonian rheological behavior at $25^{\circ} \mathrm{C}$ (Figure 3) and $33{ }^{\circ} \mathrm{C}$ (Figure 4). According to power law equation, $\mathrm{n}$ and $\mathrm{K}$ values were calculated and were shown in Table 4. F1 and $\mathrm{F} 3$ formulations were determined based on the $\mathrm{n}<1$ value obtained from the power law equation where it shows shear thinning properties in viscosity measurements at $25{ }^{\circ} \mathrm{C}$. In thermosensitive hydrogels, the viscosity increases as the temperature increases to form an expected gel structure. At $33{ }^{\circ} \mathrm{C}$, both formulations gelled above the sol/gel transition temperature. F1 formulation continued to show shear thinning properties (Figure 3), while F3 formulation has started to show shear thickening properties (Figure 4). As Todica et al. found that the $\mathrm{K}$ value and viscosity increased as the temperature increased at constant gel concentration. As the gel concentration increased, $\mathrm{K}$ value and viscosity increased as expected [41]. Similarly, as shown in a study by Rahimi S. and Natan B., it appeared that the $\mathrm{K}$ value increased with increasing gel concentration and temperature [42]. The 
higher viscosity of the F3 formulation than the F1 can be explained by the higher P407 ratio, which has a higher molecular weight and has a different PEO/PPO ratio than the P188 [43].

In F1 and F3 formulations, containing 5\% HPMC, ratio of P407 and P188 changed but the total polymer amount kept constant. While the F3 formulation was expected to exhibit a shear thinning property such as F1, it showed a shear thickening property as the rheological properties were dependent on the polymer type rather than the total polymer ratio. This may be due to the increased probability of intermolecular contact, which leads to an increase in physicochemical interactions due to the increase in flow rate. Increased physicochemical interactions may cause shear thickening behavior [44].

Table 4. K, $n, \mathrm{R}^{2}$ and Standard Error $( \pm \mathrm{SE})$ values obtained by applying power law equation to the results of viscosity measurements at $25^{\circ} \mathrm{C}$ and $33^{\circ} \mathrm{C}$.

\begin{tabular}{|c|c|c|c|}
\hline \multicolumn{2}{|c|}{ Power Law Equation } & F1 & F3 \\
\hline \multirow{3}{*}{$33^{\circ} \mathbf{C}$} & $\mathbf{K}$ & 4084 & 3662 \\
\cline { 2 - 4 } & $\mathbf{n}$ & 0.75 & 1.14 \\
\cline { 2 - 4 } & $\mathbf{R}^{2}$ & 0.9758 & 0.9737 \\
\cline { 2 - 4 } & $\pm \mathbf{S E}$ & 0.02 & 0.01 \\
\hline \multirow{3}{*}{$\mathbf{2 5}^{\circ} \mathbf{C}$} & $\mathbf{K}$ & 1096 & 841 \\
\cline { 2 - 4 } & $\mathbf{n}$ & 0.87 & 0.86 \\
\cline { 2 - 4 } & $\mathbf{R}^{2}$ & 0.9115 & 0.9168 \\
\cline { 2 - 4 } & $\pm \mathbf{S E}$ & 0.01 & 0.01 \\
\hline
\end{tabular}

\section{Texture profile analysis of formulations}

Some features of the developed formulation such as ease of removability of the product from the container, good spradability and mucoadhesion, and acceptable viscosity contribute to easy administration and increase in patient compliance. Texture profile analysis is important for the gel formulations developed to show the desired properties in the oral mucosa. Low hardness, high residence time on mucosa and easy application are among the desired properties in oral gel formulations [28]. Lower values of resilience in TPA express greater formulation elasticity [45]. Adhesiveness determines proper gel contact and retention at the mucosal surface. The cohesiveness determines the reconstruction ability of the gel after application. The high cohesiveness value increases the performance of the product. High gel adhesiveness and cohesiveness provide prolonged adhesion of the gel onto the oral mucosa and full structural recovery of the gel following application [46]. The values of hardness, adhesiveness, cohesiveness, and resilience were shown in Table 5. The 
effect of the poloxamer type was evaluated in the formulations. For F1 formulation, containing P407/P188 (15\%:20\% w/w), mechanical properties such as hardness, cohesiveness and adhesiveness were found to be lower than for F3 formulation which contains P407/P188 (20\%:15\% w/w). F1 exhibited minimum hardness, adhesiveness, cohesiveness, and maximum resilience with decreasing concentration of P407. Baloglu et al. also showed that the decrease in P407 caused low hardness, cohesiveness, adhesiveness and high resilience [15].

Table 5. Hardness, adhesiveness, cohesiveness and resilience values obtained from texture profile analyses of the $\mathrm{F} 1$ and $\mathrm{F} 3$ formulations at $33{ }^{\circ} \mathrm{C}(\mathrm{n}=3)$.

\begin{tabular}{|c|c|c|c|c|}
\hline $\begin{array}{c}\text { Formulatio } \\
\text { ns }\end{array}$ & $\begin{array}{c}\text { Hardness } \\
(\mathbf{g})\end{array}$ & $\begin{array}{c}\text { Adhesiveness } \\
\text { (g.sec) }\end{array}$ & $\begin{array}{c}\text { Cohesiveness } \\
\text { (g.sec) }\end{array}$ & Resilience \\
\hline F1 & $251 \pm 32.5$ & $-78.3 \pm 12.5$ & $0.94 \pm 0.05$ & $0.14 \pm 0.03$ \\
\hline F3 & $845 \pm 89.2$ & $-263 \pm 146$ & $1.03 \pm 0.35$ & $0.24 \pm 0.03$ \\
\hline
\end{tabular}

\section{Evaluation of ex-vivo mucoadhesion studies of the gel formulations}

The mucoadhesive characteristics are important to provide prolonged residence time of gel formulations on the mucosal surface. In this study, HPMC was used as a mucoadhesive polymer. The effects of poloxamer types on mucoadhesion properties were evaluated. The values of mucoadhesion of formulations were shown in Table 6. Mucoadhesive properties of F1 formulation were found to be lower than F3 formulation. According to the results obtained, the mucoadhesive force and work of mucoadhesion of the formulations increased with increasing P407 concentration. Baloglu et al. also showed that P407 increased the mucoadhesive force of the formulations [15]. Mucoadhesion is related to the elasticity of the polymer chains thus a high elasticity is required for strong mucoadhesive between the polymer and the mucosal surface [47]. Although the F1 formulation showed better elasticity, the higher P407 ratio and adhesiveness of the F3 formulation may have resulted in a better mucoadhesive property.

Table 6. Adhesiveness and work of mucoadhesion values obtained from ex-vivo mucoadhesion studies of the $\mathrm{F} 1$ and $\mathrm{F} 3$ formulations on bovine cheek at $33^{\circ} \mathrm{C}(\mathrm{n}=3)$.

\begin{tabular}{|c|c|c|}
\hline Formulations & Peak Force (Adhesiveness) (N) & Work of Mucoadhesion (N.sec) \\
\hline F1 & $0.01 \pm 0.00$ & $0.01 \pm 0.00$ \\
\hline F3 & $0.18 \pm 0.01$ & $0.218- \pm 0.02$ \\
\hline
\end{tabular}




\section{In vitro drug release study}

F1 and F3 formulations showed similar profiles in an in vitro release study conducted with the method of Franz diffusion cell in SS pH 6.8 saliva medium at $33{ }^{\circ} \mathrm{C}$. In the 8-hour period, the F1 formulation released $43.02 \%$ of the Metronidazole it contains, while the F3 formulation released $41.37 \%$ (Figure 5). In a recent study, metronidazole release at $\mathrm{pH} 6.8$ medium from the formulation containing $15 \%$ HPMC was resulted with $23.37 \%$ after 3 hours. [48]. In our study we obtained similar release data at the end of 3 hours with the same release medium. Ibrahim et al. developed a vaginal gel containing metronidazole using P407 and P188 in the same proportions as F1 formulation, and metronidazole release was observed to be above $80 \%$ within 1.5 hours. They also found that metronidazole release in gels containing P407 and P188 in the same proportions as F3 formulation was around $40 \%$ within 1.5 hours. The difference in release rates may have been caused by different conditions, such as higher temperature $\left(37^{\circ} \mathrm{C}\right)$ or higher acidity (pH 4.5) [39]. In addition, HPMC used in gel formulations that we developed may decrease metronidazole release rate due to the tightening of the polymeric matrix structure of the gel and extending the diffusion distance of metronidazole [37].

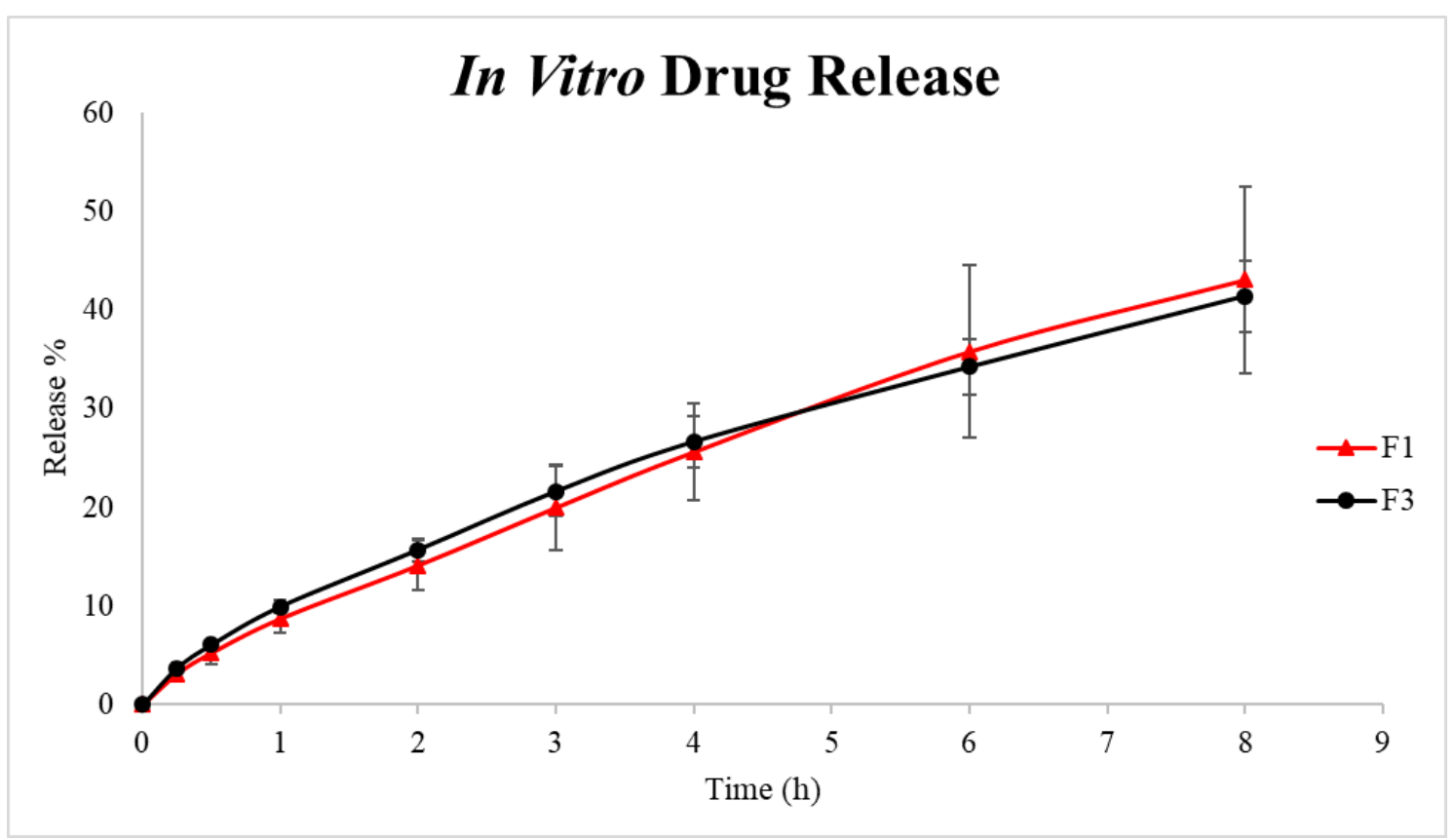

Figure 5. In vitro drug release studies from F1 and F3 formulations containing Metronidazole (0.5 $\% \mathrm{w} / \mathrm{w})$ from dialysis membrane at 6.8 phosphate buffer medium and $33{ }^{\circ} \mathrm{C}(\mathrm{n}=3)$. The square represents the F1 formulation and the circle represents the F3 formulation. 


\section{Drug release kinetic profiles}

$\mathrm{r}^{2}$ adj, AIC and MSC were chosen as fitting factors to determine the appropriate model. The AIC value is desired to be low while the MSC value is desired to be high, and the $\mathrm{r}^{2}$ adj value close to 1 indicates the suitability of the model [31]. Considering these criteria, it was determined that F1 formulation fit Korsmeyer-Peppas and F3 formulation fit to both Korsmeyer-Peppas and Weibull models (Table 7). Although F1 formulation shows the compatibility of $\mathrm{r}^{2}$ adj and MSC values to Weibull model, it is not accepted to be suitable for this model due to its high AIC value.

In the Korsmeyer-Peppas model, $\mathrm{n}$ value is used to explain the mechanism of release. The $\mathrm{n}$ value of 0.5 indicates that the release mechanism is Fickian diffusion. If it is in the range of $0.5-1$, this indicates that the release occurs with non-Fickian diffusion. $n=1$ indicates that it fits to the Case II (Zero Order) model [49]. The $\mathrm{n}$ values of the F1 and F3 formulations were determined as 0.7590 and 0.6966 , respectively. It was observed that the release from both formulations occurred by the non-Fickian diffusion mechanism.

$\beta$ value $(\beta<0.75$ Fickian release, $0.75<\beta<1$ combined release mechanism and $\beta>1$ complex release mechanism) is the constant that describes the release mechanisms of the active substance in the Weibull model. The $B$ constant in the Weibull model of the F3 formulation was found to be 0.7613. This value indicates that the release occurs with the combined release mechanism [50]. Both the $\beta$ and the $n$ values of the $\mathrm{F} 3$ formulation indicate that the release mechanism is non-fickian.

Inal et al. suggested that the poloxamer formulations fitting the Korsmeyer-Peppas model conform to this model due to the release by gel erosion mechanism [37]. There are various poloxamer gel formulations in the literature that fit different release kinetics such as zero order and Higuchi model $[51,52]$.

The first order kinetics used to describe the form of release was found to be the most suitable model for release profiles of both formulations. The non-fickian release mechanism obtained from the Korsmeyer-Peppas and Weibull models supports that the release can be achieved by first order.

In the equation of the curve obtained by applying Korsmeyer-Peppas model to in vitro experimental drug release data of $\mathrm{F} 1$ formulation, when $\mathrm{t}=24 \mathrm{~h}$, the percentage of the drug release was found to be $98.44 \%$ (not-shown). This result indicates that the continuous presence of metronidazole in the oral mucosa can be achieved by once a day administration. 
Table 7. Adjusted coefficient of determination ( $\left.\mathrm{r}^{2} \mathrm{adj}\right)$, Akaike information criterion (AIC) and model selection criteria (MSC) for different release kinetic models collected from DDsolver® by applying experimental in vitro drug release data.

\begin{tabular}{|c|c|c|c|}
\hline \multirow[t]{2}{*}{ Mathematical Models } & \multirow{2}{*}{$\begin{array}{c}\text { Compliance } \\
\text { Criteria }\end{array}$} & \multicolumn{2}{|c|}{ Formulations } \\
\hline & & F1 & F3 \\
\hline \multirow[t]{3}{*}{ Zero Order } & $\mathbf{r}^{2}$ adj & 0.9726 & 0.9356 \\
\hline & AIC & 36.8961 & 43.8792 \\
\hline & MSC & 3.2057 & 2.3088 \\
\hline \multirow[t]{3}{*}{ First Order } & $\mathbf{r}^{2}$ adj & 0.9936 & 0.9751 \\
\hline & AIC & 22.8298 & 35.3071 \\
\hline & MSC & 4.7686 & 3.2612 \\
\hline \multirow[t]{3}{*}{ Higuchi } & $\mathbf{r}^{2}{ }_{\text {adj }}$ & 0.9329 & 0.9639 \\
\hline & AIC & 45.0320 & 38.6836 \\
\hline & MSC & 2.3017 & 2.8861 \\
\hline \multirow[t]{4}{*}{ Korsmeyer-Peppas } & $\mathbf{r}^{2}{ }_{\text {adj }}$ & 0.9979 & 0.9987 \\
\hline & AIC & $\mathbf{1 3 . 7 8 0 7}$ & 8.0370 \\
\hline & MSC & 5.7741 & 6.2913 \\
\hline & $\mathbf{n}$ & 0.7590 & 0.6966 \\
\hline \multirow[t]{3}{*}{ Hixson-Crowell } & $\mathbf{r}^{2}{ }_{\text {adj }}$ & 0.9892 & 0.9648 \\
\hline & AIC & 27.9657 & 38.4336 \\
\hline & MSC & 4.1980 & 2.9139 \\
\hline \multirow[t]{4}{*}{ Weibull } & $\mathbf{r}^{2}{ }_{\text {adj }}$ & 0.9956 & 0.9985 \\
\hline & AIC & 21.3049 & 8.8481 \\
\hline & MSC & 4.9381 & 6.2011 \\
\hline & B & 0.9231 & 0.7613 \\
\hline
\end{tabular}

\section{Spraying ability assay}

F1 formulation was observed to be easily sprayable both at room temperature and after being removed from the refrigerator (Figure 6A and C). On the other hand, the F3 formulation was not sprayed as desired after it was freshly removed from the refrigerator (Figure 6D). At room temperature, no spraying occurred and F3 formulation came out as a leak from the pump (Figure $6 \mathrm{~B})$. The failure of the F3 formulation to be sprayed can be explained by its higher viscosity than the F1 formulation [53]. 


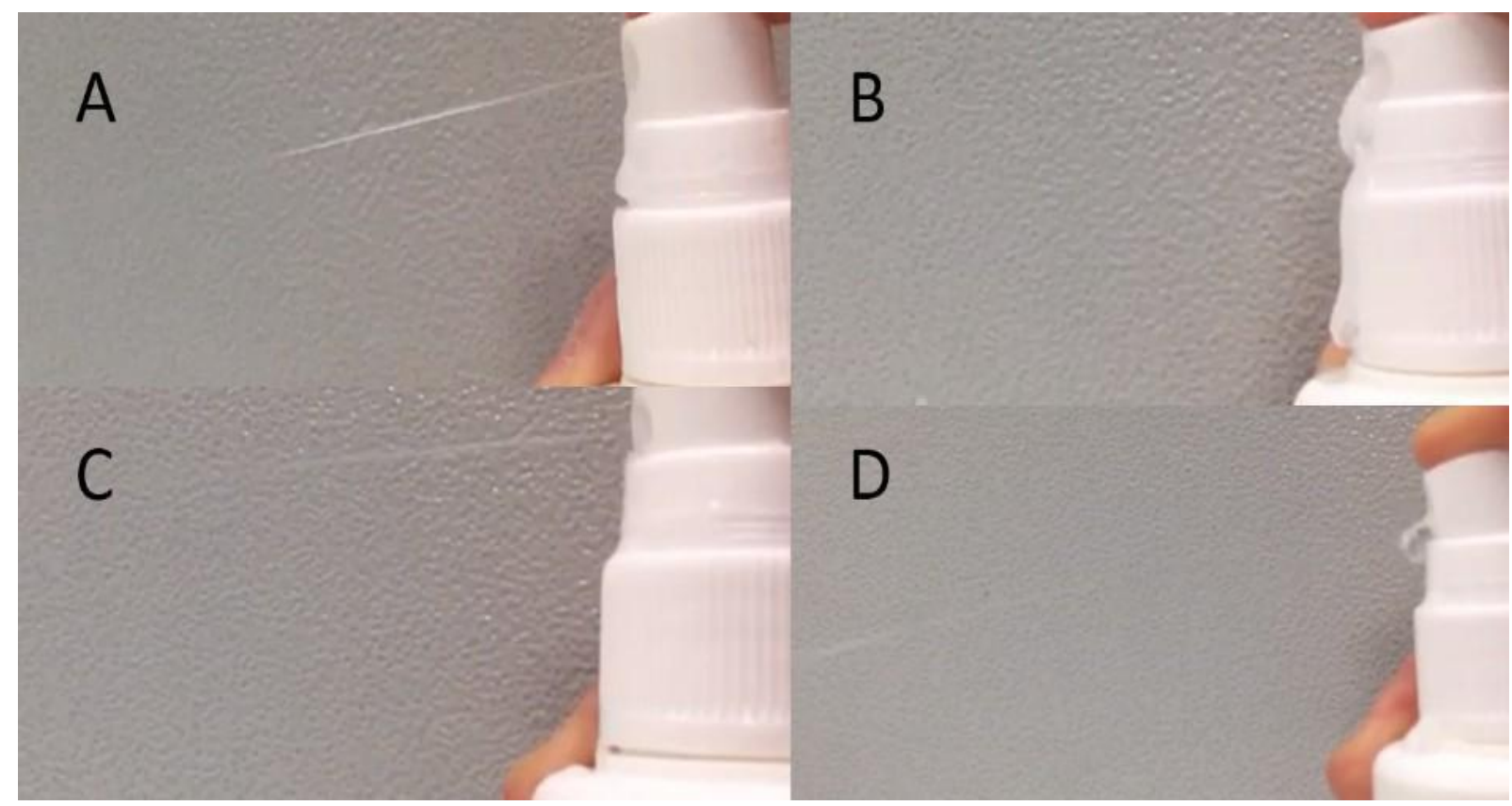

Figure 6. A) Spraying of the F1 formulation at room temperature, B) Spraying of the F3 formulation at room temperature, C) Spraying of the F1 formulation after removing it fresh from the refrigerator and D) Spraying of the F3 formulation after removing it fresh from the refrigerator.

In this study, we aim to develop thermosensitive and mucoadhesive gel formulations for oral mucositis treatment containing metronidazole, poloxamer and HPMC. We selected the optimum formulations by comparing free gel formulations with the appropriate gelling temperature and gelling time for the oral mucosa. The addition of metronidazole caused changes in the gelling temperature, and F1 formulation was within the desired range, while the F3 formulation fell below it. In addition to the gelling temperature, the lower hardness, lower resilience, better spraying ability, and pseudoplastic viscosity properties of the F1 formulation were more suitable for application to the site of action. The release of around $43 \%$ in 8 hours indicates that the desired controlled release has been achieved with optimum formulation. F1 formulation, which has the desired properties in the majority of the studies, has been determined as a candidate formulation for the future studies.

\section{CONFLICT OF INTEREST}

The authors declare no conflict of interest. 


\section{REFERENCES}

1. Lalla, R. V., Peterson, D. E. (2005). Oral mucositis. Dental Clinics of North America, 49 (1 SPEC.ISS.), 167-184.

2. Trotti, A., Bellm, L.A., Epstein, J. B., Frame, D., Fuchs, H. J., Gwede, C. K., Komaroff, E., Nalysnyk, L., Zilberberg, M.D. (2003). Mucositis incidence, severity and associated outcomes in patients with head and neck cancer receiving radiotherapy with or without chemotherapy: A systematic literature review. Radiotherapy and Oncology, 66 (3), 253-62.

3. Itoh, Y., Kubota, S., Kawamura, M., Nomoto, Y., Murao, T., Yamakawa, K., Ishihara, S., Hirasawa, N., Asano, A., Yanagawa, S., Naganawa, S. (2016). A multicenter survey of stage T1 glottic cancer treated with radiotherapy delivered in 2.25-Gy fractions in clinical practice: An initial 5-year analysis. Nagoya Journal of Medical Science, 78 (4), 399-406.

4. Donnelly, J. P., Bellm, L. A., Epstein, J. B., Sonis, S. T., Symonds, R. P. (2003). Antimicrobial therapy to prevent or treat oral mucositis. Lancet Infectious Diseases, 3 (7), 405-412.

5. Mosel, D. D., Bauer, R. L., Lynch, D. P., Hwang, S. T. (2011). Oral complications in the treatment of cancer patients. Oral Diseases, 17 (6), 550-559.

6. Villa, A., Sonis, S. T. (2015). Mucositis: Pathobiology and management. Current Opinion in Oncology, 27 (3), 159-164.

7. Chan, A., Ignoffo, R.J. (2005). Survey of topical oral solutions for the treatment of chemoinduced oral mucositis. Journal of Oncology Pharmacy Practice, 11 (4), 139-143.

8. Buchsel, P. C. (2008). Polyvinylpyrrolidone-sodium hyaluronate gel (Gelclairß): A bioadherent oral gel for the treatment of oral mucositis and other painful oral lesions. Expert Opinion on Drug Metabolism and Toxicology, 4 (11), 1449-1454.

9. Carl, W., Emrich, L. S. (1991). Management of oral mucositis during local radiation and systemic chemotherapy: A study of 98 patients. The Journal of Prosthetic Dentistry, 66 (3), 361-369.

10. Leiknes, T., Leknes, K. N., Böe, O. E., Skavland, R. J., Lie, T. (2007). Topical use of a metronidazole gel in the treatment of sites with symptoms of recurring chronic inflammation. Journal of Periodontology, 78 (8), 1538-1544.

11. Jones, D. S., Woolfson, A. D., Brown, A. F., Coulter, W. A., McClelland, C., Irwin, C. R. (2000). Design, characterisation and preliminary clinical evaluation of a novel mucoadhesive topical formulation containing tetracycline for the treatment of periodontal disease. Journal of Controlled Release, 67 (2-3), 357-368.

12. Kaur, J., Kaur, J., Jaiswal, S., Gupta, G. (2016). Recent advances in topical drug delivery system. Pharmaceutical Research, 6 (07), 6353-6369. 
13. Patil, P. B., Datir, S. K., Saudagar, R. B. (2019). A review on topical gels as drug delivery system P.B. Journal of Drug Delivery and Therapeutics, 3 (3-s), 989-994.

14. Agrawal, A. K., Das, M., and Jain, S. (2012). In situ gel systems as "smart" carriers for sustained ocular drug delivery. Expert Opinion on Drug Delivery, 9 (4), 383-402.

15. Baloglu, E., Karavana, S. Y., Senyigit, Z. A., Guneri, T. (2011). Rheological and mechanical properties of poloxamer mixtures as a mucoadhesive gel base. Pharmaceutical Development and Technology, 16 (6), 627-636.

16. Kabanov, A. V., Batrakova, E. V., Miller, D. W. (2003). Pluronic ${ }^{\circledR}$ block copolymers as modulators of drug efflux transporter activity in the blood-brain barrier. Advanced Drug Delivery Reviews, 55 (1), 151-164.

17. Maynard, C., Swenson, R., Paris, J. A., Martin, J. S., Hallstrom, A. P., Cerqueira, M. D., Weaver, W. D. (1998). Randomized, controlled trial of RheothRx (poloxamer 188) in patients with suspected acute myocardial infarction. American Heart Journal, 135(5 I), 797804.

18. Singh, S., Parhi, R., Garg, A. (2011). Formulation of topical bioadhesive gel of aceclofenac using 3-level factorial design. Iranian Journal of Pharmaceutical Research, 10 (3), 435-45.

19. Shin, S. C., Kim, J. Y., Oh, I. J. (2000). Mucoadhesive and physicochemical characterization of Carbopol-poloxamer gels containing triamcinolone acetonide. Drug Development and Industrial Pharmacy, 26 (3), 307-312.

20. BASF Web site. (2017). Retrieved May 22, 2020, from https://pharmaceutical.basf.com/

21. Valenta, C. (2005). The use of mucoadhesive polymers in vaginal delivery. Advanced Drug Delivery Reviews, 57 (11), 1692-712.

22. Tuğcu-Demiröz, F. (2017). Development of in situ poloxamer-chitosan hydrogels for vaginal drug delivery of benzydamine hydrochloride: Textural, mucoadhesive and in vitro release properties. Marmara Pharmaceutical Journal, 21 (4), 762-770.

23. Marques, M. R. C., Loebenberg, R., Almukainzi, M. (2011). Simulated biological fluids with possible application in dissolution testing. Dissolution Technologies, 18 (3), 15-27.

24. Tuğcu-Demiröz, F., Acartürk, F., Özkul, A. (2015). Preparation and characterization of bioadhesive controlled-release gels of cidofovir for vaginal delivery. Journal of Biomaterials Science, Polymer Edition, 26 (17), 1237-1255.

25. Tuğcu-Demiröz, F., Acartürk, F., Erdoğan, D. (2013). Development of long-acting bioadhesive vaginal gels of oxybutynin: Formulation, in vitro and in vivo evaluations. International Journal of Pharmaceutics, 457 (1), 25-39.

26. Patel, P., Varshney, P., Rohit, M. (2014). Analytical method development and validation for simultaneous estimation of metronidazole and amoxicillin in synthetic mixture by UV- 
visible spectroscopy. International Journal of Pharmacy and Pharmaceutical Sciences, 6 (SUPPL. 2), 317-319.

27. de Francisco, L. M. B., Rosseto, H. C., de Alcântara Sica de Toledo, L., dos Santos, R.S., de Souza Ferreira, S. B., Bruschi, M. L. (2019). Organogel composed of poloxamer 188 and passion fruit oil: Sol-gel transition, rheology, and mechanical properties. Journal of Molecular Liquids, 289, 111170.

28. Jones, D.S., Woolfson, A. D., Brown, A. F. (1997). Textural, viscoelastic and mucoadhesive properties of pharmaceutical gels composed of cellulose polymers. International Journal of Pharmaceutics, 151 (2), 223-233.

29. Amasya, G., Karavana, S. Y., Şen, T., Baloğlu, E., Tarimci, N. (2012). Bioadhesive and mechanical properties of triamcinolone acetonide buccal gels. Turkish Journal of Pharmaceutical Sciences, 9 (1), 1-11.

30. Cevher, E., Taha, M. A. M., Orlu, M., Araman, A. (2008). Evaluation of mechanical and mucoadhesive properties of clomiphene citrate gel formulations containing carbomers and their thiolated derivatives. Drug Delivery, 15 (1), 57-67.

31. Sorasitthiyanukarn, F. N., Rojsitthisak, P., Rojsitthisak, P. (2017). Kinetic study of chitosanalginate biopolymeric nanoparticles for the controlled release of curcumin diethyl disuccinate. Journal of Metals, Materials and Minerals, 27 (2), 17-22.

32. Mehravaran, N., Moghimi, H., Mortazavi, S. A. (2009). The influence of various mucoadhesive polymers on in vitro performance of the resulting artificial saliva pump spray formulations. Iranian Journal of Pharmaceutical Research, 8 (1), 3-13.

33. Lapum, J., Verkuyl, M., Garcia, W., St-Amant, O., Tan, A. (2018). Vital Sign Measurement Across the Lifespan, 1st Canadian edition, Springer, Toronto, p. 26.

34. Moore, R. J., Watts, J. T. F., Hood, J. A. A., Burritt, D. J. (1999). Intra-oral temperature variation over 24 hours. European Journal of Orthodontics, 21(3), 249-261.

35. Ban, E., Park, M., Jeong, S., Kwon, T., Kim, E. H., Jung, K., Kim, A. (2017). Poloxamerbased thermoreversible gel for topical delivery of emodin: Influence of P407 and P188 on solubility of emodin and its application in cellular activity screening. Molecules, 22 (2), 246.

36. Zhang, K., Shi, X., Lin, X., Yao, C., Shen, L., Feng, Y. (2015). Poloxamer-based in situ hydrogels for controlled delivery of hydrophilic macromolecules after intramuscular injection in rats. Drug Delivery, 22 (3), 375-382.

37. Inal, O., Yapar, E. A. (2013). Effect of mechanical properties on the release of meloxicam from poloxamer gel bases. Indian Journal of Pharmaceutical Sciences, 75 (6), 700-706.

38. Koffi, A. A., Agnely, F., Ponchel, G., Grossiord, J. L. (2006). Modulation of the rheological and mucoadhesive properties of thermosensitive poloxamer-based hydrogels intended for the rectal administration of quinine. European Journal of Pharmaceutical Sciences, 27 (4), 
$328-335$.

39. Ibrahim, E. S. A., Ismail, S., Fetih, G., Shaaban, O., Hassanein, K., Abdellah, N. H. (2012). Development and characterization of thermosensitive pluronic-based metronidazole in situ gelling formulations for vaginal application. Acta Pharmaceutica, 62 (1), 59-70.

40. Tirnaksiz, F., Robinson, J. R. (2005). Rheological, mucoadhesive and release properties of Pluronic F-127 gel and Pluronic F-127/polycarbophil mixed gel systems. Pharmazie, 60 (7), $518-23$.

41. Todica, M., Pop, C. V., Udrescu, L., Pop, M. (2010). Rheological behavior of some aqueous gels of carbopol with pharmaceutical applications. Chinese Physics Letters, 27 (1), 018301.

42. Rahimi, S., Natan, B. (2000). Numerical solution of the flow of power-law gel propellants in converging injectors. Propellants, Explosives, Pyrotechnics, 25 (4), 203-212.

43. Franzén, H. M., Draget, K. I., Langebäck, J., Nilsen-Nygaard, J. (2015). Characterization and properties of hydrogels made from neutral soluble chitosans. Polymers, 7, 373-389.

44. Liu, W.H., Yu, T.L., Lin, H.L. (2007). Shear thickening behavior of dilute poly(diallyl dimethyl ammonium chloride) aqueous solutions. Polymer, 48 (14), 4152-4165.

45. Jones, D. S., Woolfson, A. D., Djokic, J. (1996). Texture profile analysis of bioadhesive polymeric semisolids: Mechanical characterization and investigation of interactions between formulation components. Journal of Applied Polymer Science, 61 (12), 2229-2234.

46. Tan, Y. T. F., Peh, K. K., Al-Hanbali, O. (2000). Effect of carbopol and polyvinylpyrrolidone on the mechanical, rheological, and release properties of bioadhesive polyethylene glycol gels. AAPS PharmSciTech, 1 (3), E24.

47. Cevher, E., Sensoy, D., Taha, M. A. M., Araman, A. (2008). Effect of thiolated polymers to textural and mucoadhesive properties of vaginal gel formulations prepared with polycarbophil and chitosan. AAPS PharmSciTech, 9 (3), 953-65.

48. Sarkar, U., Raha, A., Mukherjee, P., Paul, M., Bagchi, A. (2018). Development and evaluation of Metronidazole containing topical gel using different gelling agents. Asian Journal of Pharmacy and Pharmacology, 4 (6), 785-789.

49. Zhang, Y., Huo, M., Zhou, J., Zou, A., Li, W., Yao, C., Xie, S. (2010). DDsolver: An addin program for modeling and comparison of drug dissolution profiles. The AAPS Journal, 12 (3), 263-271.

50. Soares, P. I. P., Sousa, A. I., Silva, J. C., Ferreira, I. M. M., Novo, C. M. M., Borges, J. P. (2016). Chitosan-based nanoparticles as drug delivery systems for doxorubicin: Optimization and modelling. Carbohydrate Polymers, 147 304-312.

51. Wang, Y., Jiang, S., Wang, H., Bie, H. (2017). A mucoadhesive, thermoreversible in situ nasal gel of geniposide for neurodegenerative diseases. PLoS ONE, 12 (12), e0189478. 
52. Parhi, R. Suresh, P. (2015). Alginate-poloxamer beads for controlled release of metoprolol succinate. Turkish Journal of Pharmaceutical Sciences, 12 (1), 59-66.

53. Mori, N. M., Patel, P., Sheth, N. R., Rathod, L. V., Ashara, K.C. (2017). Fabrication and characterization of film-forming voriconazole transdermal spray for the treatment of fungal infection. Bulletin of Faculty of Pharmacy, Cairo University, 55 (1), 41-51. 